\title{
Foreword
}

\section{Antonio Strati}

The essays in this volume edited by Federica De Molli and Marilena Vecco provide the state of the art of the organizational study of the spatial dimension of organizations operating in the creative and cultural industries. Much is learned about organizing in these social contexts thanks also to the empirical research that is illustrated there. At the same time, the book draws the attention of organization scholars to issues that show how the debate on space in organizational life in the creative and cultural industry has its roots in the more general one concerning the conceptions of space in the sociology of organization, in organizational theories and in management studies.

To fully understand the importance of this book, it is necessary to take into account the fact that the spatial dimension has been taken for granted in organizational studies for many decades and that it is due to the Cultural Turn of the 1980s that we began to "see" it. For a long time, therefore, space represented the "container", the "boundary" or the "distance" in organizational theories, just as it represented it in the study of society.

But if in the everyday organizational language space is often considered as if it were one thing, and always the same thing, so much so as to be taken for granted, on the contrary space is multiple and even fragmented, as Georg Simmel (1903) pointed out in his writings on the sociology of space. For each specific particle of space there is an aspect of uniqueness that can have sociological relevance to understand social formations such as states, communities, organizations in general and organizations operating in the creative and cultural sectors in particular. In other words, social formations acquire a character of uniqueness or exclusivity also thanks to the specificities of the space they inhabit.

So, let's examine more precisely what I mean by "seeing" the organizational space in the organizational research carried out in the contexts of the creative and cultural industry and, therefore, the importance that this book assumes in the study of organization. 


\section{Art, Space, Practice}

In order to illustrate to the reader the sociological importance of "seeing the space" in the study of organizational life in the creative and cultural sectors, I shall take inspiration from a work of art exhibited in a museum. It is Bit.Fall by the German artist Julius Popp that I saw, for the first time, in the Mona Roma museum in Hobart in Tasmania. Art, science and management of the creative and cultural industry are mixed in it. On one side, says Popp (2006) in a video in which he illustrates his artistic work, "scientific machines are generated which also work as sculptures" while, on the other side, "pictures emerge" and describe the processes of "how a culture actually functions" in our contemporary societies.

The black and white photograph, Playing with Julius Popp's "Bit-Fall", in Figure 1 shows a detail of the artwork, the upper part: a word, "organization", white, with a large wall carved into the rock behind it and illuminated from above by eight lamps fixed to a metal structure, dominates it arranged along the entire width of the rock wall.

The word "organization" is poorly defined, as if it were made of white dots detached from each other. This is because it is written by a waterfall. It appears, therefore, for a very short instant, that is, for the time it takes for the drops of water to fall and be collected in a stainless-steel basin at the bottom, at the foot of the rocky wall. As soon as "organization" plunges into the basin and disappears, another word appears at the top, right under the lamps, and then disappears in turn in an instant and thus leaves the scene for yet another word.

I felt like something magical was giving warmth to both the rock face and the metal structures that supported the lamps that the photograph shows and the water sources that remain invisible. Furthermore, the cascade of water meant that the succession of words - i.e. change, climate, committee, Agency, Protection, automobiles, shopping, and others - did not appear as the succession of written words, but as the continuous metamorphosis of white-colored words that, initially short, then stretched out to vanish when falling. The drops of water that were writing the words fell and made noise. We visitors too made noise, with our footsteps, however attentive, with our voices, however subdued, and with the photographs. Natural, human or mechanical noises that mingled with each other in a jumble of rhythms. 


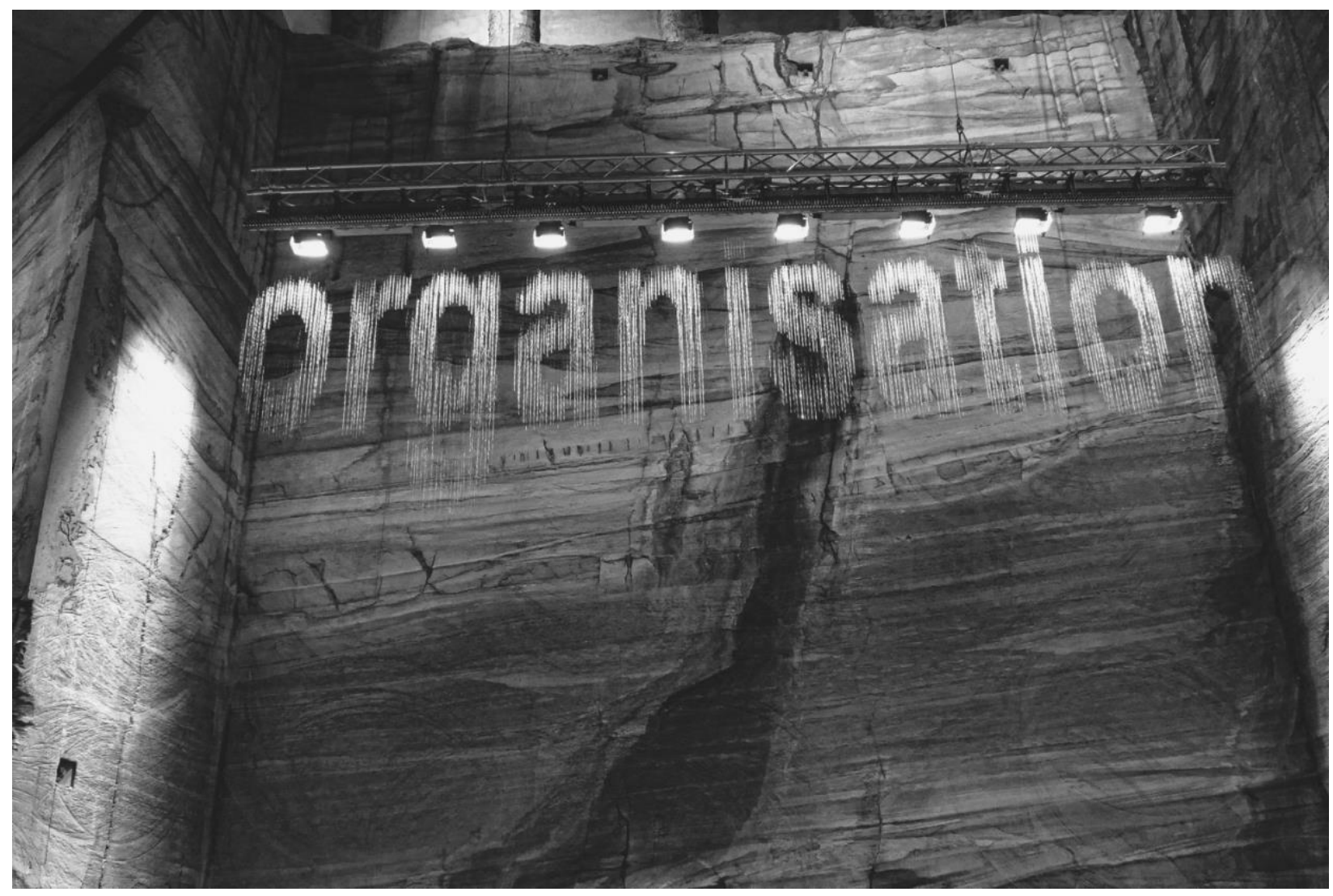

Figure 0.1 Playing with Julius Popp's “Bit.Fall”. File Leica C, software Adobe Lightroom

A jumble of rhythms that I listened to and a mixture of sensations that those words written by water gave me. Some of them didn't tell me much. Others, however, struck me. Like the word "organization", whose appearance surprised me to the point that I waited for it to reappear to try to photograph it. Attempt, as in a game between my skills as a photographer and Julius Popp's artwork, since those words written by the water I didn't have time to see them appear that had already disappeared. Playing to give vent to the amazement felt, for the magic of that unadorned and essential corner of the museum space in which I was actually immersed and, also, for the evocative power of the awareness that those words were made of water just like myself in the act of photographing them.

But, I wondered, how did “organization" end up in the words made of water droplets? "The machine", says Julius Popp (2006) in the video,

searches independently for News in the Internet and looks for new words that emerge and according to statistic rules picks out the ones that really carry information. 
In the moment when the water drops leave the machine the letters that we can read already begin to dissolve.

That is, the information produced by the machine is valid only for a few seconds.

$[\ldots]$ The machine is a symbol for me that these meanings or values can change very fast.

These words, however, to tell the truth, are not those that Popp pronounced in the video, as we will see later, immediately after some considerations that I want to bring to the reader's attention.

\section{Corporeality, Amezement, Play}

The first consideration concerns the definition of organizational space in the creative and cultural industries that emerges from the Bit.Fall artwork exhibited at the Mona Roma museum in Tasmania.

This organizational space is certainly made up of the museum hall carved into the rock that exhibits the work of art, but not only by it. In fact, in addition to the excavation in the rock, it also consists of the algorithms of digital technology that ensure that the words are searched and selected on the Internet and that the water writes them with its drops. The organizational space is therefore not delimited by the exhibition hall or by the museum as a formal organization because the physical space of the hall and museum are connected-in-action with the work of art. This connection-inaction means that the spatial dimension of this organization that operates in the creative and cultural sectors goes beyond the physical space to immerse itself in the immaterial space of the Internet.

Likewise, the materiality of the spatial dimension is not constituted only by the physicality that the museum room, made as it is of rock and artifacts such as the artwork, the lighting system, the caption signs and the signs indicating the exhibition itinerary. Nor are the connections-in-action between the aforementioned physicality and the intangibility of the algorithms of software programs and the Internet sufficient to complete it. We do not fully understand the materiality of this organizational space if we do not also see the corporeality of the museum's visitors and those who work there. If, then, we add the physicality of the bodies of those we see - of those who work in the museum and of those who visit the Bit.Fall exhibition with us -, 
- nature, that is rock, bodies, light and water, and

- technology, both (a) the mechanical one of the structures that support the lamps and (b) the digital one of the words searched on the Internet and the computerized management of the drops of water that are able to write,

show the palpable and immaterial corporeality of this organizational space.

The palpable and immaterial corporeality of this space resonates and reveals the social practices that have shaped it and continue to shape it. Because it shows the taste, the aesthetic choice and the sensible knowledge that distinguishes those specific practices (Gherardi and Strati, 2012) thanks to which the museum hall dug into the rock was designed and built, the waterfall that writes words selected from the Internet was imagined and realized, and the style with which to visit the exhibition was learned and experienced.

In other words, it shows that the center of gravity of the organizational space of the Mona Roma museum hall changes in the connections-in-action and shows the rhythms that distinguish this space. It is a composite rhythm, because the rhythms of the words taken from the Internet, the rhythms of the drops of water from the waterfall that write them but also carry them away with them in the tank, the rhythms of breathing, gestures, passages and speeches of us visitors and of those who work at the museum alternate and intertwine. The rhythm of this organizational space is certainly given by the temporal interweaving of all these different rhythms, but it is also given by their arrangement in space because "it derives from the elementary articulation of perceptual contents in the forms of regularity and irregularity, of symmetry and asymmetry" (Catucci, 1999: 245).

This particular organizational space of Mona Roma, thus, is made up of the connections-in-action of materiality and performance of both water, light, software programs, those who work there and us visitors, and more.

The second consideration I want to make is that the organizational space tells us a lot about the organization we work in or that we are visiting for our study and research. Pasquale Gagliardi (2006: 709) observes that the "physical setting of an organization (with its formal qualities, i.e. sensorially perceptible qualities)" constitutes "the most faithful portrayal of its cultural identity". 
This is not always true, of course. I still remember that at the beginning of my studies on the aesthetic dimension of organizational life I had found a dissonance between the aesthetics of the organizational space and the aesthetic dimension of the cultural identity of the organization. It happened by studying the organizational culture of the mathematics department of a prestigious Italian university. The venue had been purposely built with the architectural intent of a rationalist aesthetic that let the atmosphere of mathematical rationality breathe in the walls themselves. But mathematicians did not find themselves in this aesthetic, because it was not rationality that gave shape to the organizational culture of the department, but the aesthetic dimension of doing mathematics centered on imagination, fantasy and beauty. Dissonance also found in subsequent research and even very recently. It happened with a renowned research structure of an Italian public administration that made a strategic organizational change and which, to facilitate it, built completely new offices, composed of open spaces, large windows that immerse themselves in nature and long corridors. An aesthetic that is always the same and characterized by greyness, said the researchers who worked there, an aesthetic that is far from expressing the variety and specificities of the prestigious international research conducted there.

However, in my visit to the Mona Roma in Hobart, it was precisely the experience of this organizational space that made me understand, carnally, that is, with my body and my capabilities of aesthetic knowledge (Strati, 2019) that museum as an organization. Sensorial knowing, aesthetic judging and poetic performing made it clear to me the explicit intent of Mona Roma to provide the visitor with the opportunity for an experiential and sensorial study of art. I was able to grasp the beauty of this organization from the organizational space - that is, the magic of water writing words taken from the Internet, the amazement felt, the desire to play with the artwork - as well as its ugliness symbolized by the unadorned walls and metal structures, as well as by the gloomy atmosphere of the hall carved into the depths of the rock.

Amazement leads us to the third consideration concerning the aestheticization of organizational space in the creative and cultural industry and which I will complete with the theme of play. Pierre Guillet de Monthoux (2004) reminds us that aestheticization is a question that has distant roots in time and that concerned Richard Wagner's Bayreuth itself, a temple of art dotted with fan clubs and workshops of artistic activities that have transformed aesthetic representations in parlor games. Anestheticizing effects that have been often severely criticized by sociologists, philosophers and organizational scholars. This, however, did not prevent aestheticization from becoming a growing 
phenomenon in contemporary globalized societies. All the more so in those hybrid spaces where the corporate space combines with the public space and the domestic space giving life to new forms of working life (De Molli et al., 2020).

Aestheticization, however, highlights an important fact for understanding the spatial dimension in the creative and cultural industry: the social practice of organizational space. Raffaele Milani points this out about the Vuitton Museum in Paris. The museum designed by Frank Gehry changes and changes shape with delicacy and flexibility as we approach it and takes the shape of egg shells arranged on a large lawn, or that of a spaceship, or, again, that of a huge butterfly. Once inside we find ourselves between walls that look like sails blown up by the wind, windows that immerse us in the woods of the Bois de Boulogne, terraces from which we can see, in the distance, beyond the park, Paris that surrounds us. It is architecture that "makes a show of itself" and "the evidence of the object is given by amazement", writes Milani (2015: 119), while the museum "constantly invites us to look, to discover, between staggered levels in which we are invited to venture".

Play further highlights the experience of organizational space, moving and changing points of view and the feeling of pleasure that one feels doing this. I wrote above that it was the appearance of the term "organization" among the words written by the waterfall that aroused in me the desire to "play with" the work of art and to see if I would be able to "write" it in my turn with the pixels of a digital photograph, instead of with water droplets. It was then, when I created a "play with" the artwork placed in that part of the museum hall, that I felt as if I had finally entered that organizational space and could, therefore, also leave it because I had found my way to understand it. Play has the power to create connections-in-action between artistic humanities and organizational theorizations, which give form to a non-representational research (Hjorth et al., 2018) of organizational space, in general, and of the spatial dimension in the creative and cultural sectors, in particular.

I close these considerations by recalling that they refer to the "institutionalized aesthetic space". A particular space, observes Gioa Laura Iannilli (2019: 222-223), which "generally includes all those dimensions to which the aesthetic, typically reduced to the artistic, has been institutionally recognized as a distinctive feature" even if it refers to spaces that traditionally they are not considered aesthetic or artistic, such as industrial spaces (active and no longer active), fashion and design districts or even food and wine itineraries. 
Now let's go back to the question left open before: what did I mean by commenting, at the end of what Julius Popp said in the video, that, in truth, those were not the words spoken by the artist?

\section{Space Key, Empty Space, Space Silent}

The words attributed to Popp, in fact, are not those that the artist pronounced. They are in English, while Popp speaks German in the video, a fresh and pleasant German to my hearing. I know too little German to be able to transcribe it. I therefore relied not on listening to the words I heard, but on reading the subtitles I saw. I watched and re-examined the video's subtitles and then chose a few short passages. I interrupted the flow of images and sounds by pressing the "space" key on my computer keyboard, transcribed the words read and, by pressing the "space" key on the keyboard again, I moved to the next screen.

If with the scrolling of the video my senses - of sight and hearing above all - were activated to capture the flow of images, sounds and aesthetic atmospheres, with the static screen of the subtitles the sense of sight had become hegemonic. Also, touch became the master of time - due to the skill with which I pressed the keys to write the words to be transcribed -, while the sense of hearing was limited to listening to the noise caused by the pressure of the fingers on the keys.

I switched from the sensory scenario of the video scrolling to that of the static screen by pressing the "space" key. Space, in fact, is also this small organizational artifact, this object made of synthetic material, narrow and elongated so that it can be pressed with both the thumb of the left hand and that of the right hand. It has been so since the mechanical typewriters of the past. I touch it and here the experiential flow of my video vision is interrupted and a "space silent" is created that stops on a fixed image. I touch it again, and instead, the disappearance of the silent-space, or its negation, is created.

The space-key, however, does not only create the space-silent in the social practice of doing organizational research. It also creates the "empty space" in writing. In the latter case, however, if I press it again, I do not resume writing, but I write an additional blank space. The action repeats itself equal to itself, instead of becoming the opposite of itself as happens with the creation of the space-silent. 
Let's try, then, to make considerations that complement those previously made regarding the spatial dimension in the creative and cultural sectors.

The space-key - which creates and dissolves the space-silent; and which repetitively creates empty space - it is nothing more than an ordinary artifact commonly present in working life in organizations and in private life. To the point of not being generally noticed. Having "seen" it, however, allowed me to broaden the boundaries of the museum's organizational space from the hall where the Bit.Fall artwork was exhibited to include both the Internet - for the video - and the drafting of this Preface.

The space-silent is a particle of this organizational space. It is not audible; it is not seen and it is not palpable. However, it can be clearly perceived: its duration over time, rhythm and frequency can be grasped. The empty space is also a particle of the museum's organizational space. It is not audible, but is instead visible and palpable even though it is often neither seen nor touched. These fragments of organizational space, therefore, have a diverse physicality and influence our sensory faculties and our aesthetic judgment in different ways. Furthermore, they have the ability to evoke the awareness of the shadows of the organizational space, that is, of the spaces or fragments of space that are not seen - as the empty space reminds us - or even that are eliminated, as the space-silent evokes.

The space-silent, moreover, leads us to reflect on the ephemeral dimension that organizational space often assumes, especially in the cultural and creative industry sectors. It appears and disappears continuously and changes consistency continuously, because it depends on the length and difficulty of the subtitle text to be transcribed and the skill of my fingers on the keyboard. It is therefore not a fixed a priori space. Empty space, on the other hand, is by no means ephemeral, because it always remains there in front of our eyes. It is always there, and this distinguishes it from space-silent, but like the latter it is not always equal to itself. It changes continuously, in fact, depending on the formatting of the chosen text and, at the same time, it tries just as continuously to hide its mutations as if diversity were a defect, an inaccuracy. The empty space thus tries to camouflage its mutations by making use of flexibility - a fundamental characteristic of digital technologies - which gives rise to the aesthetic harmonization of the empty spaces to our sight. Technological flexibility which, that is, makes them appear to our eyes as if the empty spaces were all identical or almost identical.

Finally, a more general consideration to close this section. Space key, space silent and empty space resonate the polysemy of the term space and evoke it in terms of theoretical and methodological 
awareness in the study of organizational space in general and of organizational space in the creative and cultural sectors, in particular.

\section{Metamorphosis \& Organizational Space}

In this Preface I have mainly indicated that the organizational space does not only delineate the formal boundaries of the organization, the Weberian walls beyond which one ends up transformed into officials of the bureaucracy who have been deprived in this passage of their abilities for aesthetic understanding. On the contrary, it outlines the opposite, an organizational space that assumes its own face - changeable and in itinere - only in the course of organizational research. An organizational space which, therefore, does not already exist in itself, "pure" and with a welldefined form, before the organizational research has been conducted, but which instead takes form during the research itself.

The reader will find in the essays that make up this volume an extensive illustration and discussion, beginning with the introductory chapter of the book's editors, of the theoretical status assumed by the organizational space in organizational research conducted in the creative and cultural industry. S/he will thus be able to fully grasp the symbolic, aesthetic and instrumental meaning of the fact that organizational space is debated in terms of "metamorphosis".

However, when reading the book, s/he has to keep in mind that s/he will have to do the opposite of what I did with Popp's words. That is, s/he must not interrupt the flow of the themes presented and discussed under various profiles in the different essays that make up the book, their changing and their transformation if s/he intends to grasp their metamorphoses. Because, as I pointed out with regard to the aesthetic philosophies that have influenced and still influence organizational theory in general and aesthetic approaches to the study of organizational life in particular (Strati, 2019: 173174), it is precisely art that points this out to us: if you want to fully appreciate a Metamorphosis woodcut print created by Maurits Cornelis Escher you have to avoid cutting out a detail and separate it from the rest, because it is the flow that his Metamorphosis depicts. 


\section{References}

Catucci, S. (1999). Ritmo, in Carchia G. and P. D’Angelo (eds.), Dizionario di estetica. Roma-Bari: Editori Laterza, pp. 245-246.

De Molli, F., Mengis, J. and van Marrewijk, A. (2020). The Aestheticization of Hybrid Space: The Atmosphere of the Locarno Film Festival, Organization Studies, 41(11): 1491-1512.

Gagliardi, P. (2006). Exploring the Aesthetic Side of Organizational Life, in Clegg, S. R., Hardy, C., Lawrence, T. B. and W. R. Nord (eds.), The Sage Handbook of Organization Studies. London: Sage, pp. 701-724.

Gherardi, S. and Strati, A. (2012). Learning and Knowing in Practice-based Studies. Cheltenham, UK and Northampton, MA, USA: Edward Elgar.

Guillet de Monthoux, P. (2004). The Art Firm: Aesthetic Management and Metaphysical Marketing from Wagner to Wilson. Stanford, CA: Stanford Business Books.

Hjorth, D., Strati, A., Drakopoulou Dodd, S., and Weik, E. (2018). Organizational Creativity, Play and Entrepreneurship: Introduction and Framing, Organization Studies, 39 (2-3): 155-168.

Iannilli, G. L. (2019). L'estetico e il quotidiano: Design, Everyday Aesthetics, esperienza. Bologna: Mimesis.

Milani, R. (2015). L'arte della città. Bologna: Il Mulino. (English trans.: The Art of the City, Montreal: McGill-Queen's University Press, 2017).

Popp, J. (2006). Bit-Fall 2001-2006, Discovery Channel Short Film, YouTube, video 3.05'.

Simmel, G. (1903). Soziologie des Raumes, in Simmel, G., Gesamtausgabe, vol. 7, Frankfurt am Main: Suhrkamp, 1995, pp. 132-183. (English trans.: The Sociology of Space, in Frisby, D. and M. Fetherstone (eds.), Simmel on Culture, London: Sage, 1997, pp. 137-169). 
Strati, A. (2019). Organizational Theory and Aesthetic Philosophies. New York, NY and London, UK: Routledge.

Antonio Strati, senior professor at the Department of Sociology and Social Research, University of Trento, Italy, and chercheur associé at i3-CRG, École polytechnique, IP Paris, is both a sociologist and an art photographer. He is a founder member of RUCOLA, the Research Unit on Communication, Organizational Learning and Aesthetics of Trento, and of SCOS, the Standing Conference on Organizational Symbolism.

His book Organization and Aesthetics (Sage 1999) has been translated into several languages. He is also the author of Theory and Method in Organization Studies (Sage 2000) and recently published Organizational Theory and Aesthetic Philosophies (Routledge, 2019). 